empiristic origin of the space consciousness, the author takes the stand that ' the crude, vague feeling of extension' is ' underived by mere experience from non-spatial psychical elements.'

On the other hand, the author is confident "that all accurate knowledge of the meaning of the space relations in our space world, all practically precise perception of direction, position, contour, size, etc., is a result of experience, and could never be gained without it" (p. I4I). As to the parts played by the various senses in space perception, the author holds "that all forms of sensations are immediately suggestive of spatial attributes, $e . g$., position, size, distance, etc.; but that sight and touch possess intrinsically and completely the full spatial characteristics" (p. 142). Again, in the matter of the number of affective elements, the author prefers " to abide by the older analysis of pleasantness and unpleasantness as the two modes of affection fundamentally distinct from sensation" (p. 259).

On the whole, and largely in detail, one may say that the book is excellent. It would, however, be much improved as an instrument for teaching psychology if the substance of the topics was more frequently summed up in terse formulæ.

H. C. Stevens.

UNIVERSITY OF WASHINGTON.

\title{
RAND'S BIBLIOGRAPHY.
}

Bibliography of Philosophy, Psychology, and Cognate Subjects. Compiled by Benjamin Rand, Ph.D., Harvard University. 2 Parts. New York, Macmillan Company, 1905. Pp. xxvi + I192. The two parts together form the third volume of Baldwin's Dictionary of Philosophy and Psychology. It is a work of laborious and painstaking scholarship, and Dr. Rand has laid the philosophical world under a debt of peculiar obligation for the service which he has rendered in this compilation. The first part consists of a short section devoted to a catalogue of philosophical bibliographies, dictionaries, periodicals and other collective material. The bulk of the volume, however, is given to a bibliography of the history of philosophy, including philosophers themselves, their works and works upon them. The second part covers the special subjects of systematic philosophy, logic, æsthetics, philosophy of religion, ethics and psychology.

It may seem perhaps ungracious to criticise work which is in the main so excellent and valuable. There are, however, several minor defects which are obvious even from a cursory glance through the twelve hundred pages. The finding of any special topic would have been greatly facilitated if some guiding word had appeared at the top 
of each page. For instance, $I$ open the first volume at random and find on page i 70 the work: Thompson, $J$. Arthur. History and Theory of Heredity. One must look back to p. 166 to find the caption under which this book appears, which happens in this case to be that of Charles Robert Darwin. At the top of the page is merely the general title, too general to be a specific guide, History of Philosophy. Again, in giving the title of a book of special note, there is inserted immediately following it a supplementary list of the works which have been written upon the book in question. In this connection some indication should be more clearly given by spacing or other device as to where such parenthetical lists of books begin and end. It is not clear to the eye running hastily down the page; as, for instance, the appended list on Hegel's Outlines of Logic, on p. 663, or that on Schleiermacher's Dialektik, on p. 676.

Again, in the section at the beginning of Part II. on Systematic Philosophy there is no place in Dr. Rand's classification for the subjects of Empiricism and Rationalism, and no bibliography of these subjects giren; at least I was able to discover none. Under the head of Logic, there is no reference to the subject of Classification. I afterwards discovered several works on Classification mentioned under the head of Method, but scattered here and there with no attempt to group them together. There should be a reference in the table of contents to so important a subject as that of Classification, and then a cross-reference to the subject of Method where the works on Classification in this bibliography are to be found. Under the same head of Logic, there is no reference to the theory of Statistics, or Statistical Method, and no mention of any works on this subject under the sub-head of Method. There is nothing under the heads of Nominalism, Realism and Conceptualism. I notice also some conspicuous omissions of important works here and there as I have happened to turn to certain topics as the result of a chance suggestion.

Under Evolution, there is no reference to Huxley's Romanes Lectures on Ethics and Evolution, or to De Vries' Species and Varieties: Their Origin by Mutation. Under Symbolic Logic, Lewis Carroll's Symbolic Logic, Couturat's L'algèbre de la logique, the volume of Johns Hopkins Studies and the works of Frege are omitted. Under the head of Probability there is no mention of Venn's Logic of Chance, or Pearson's Grammar of Science, or the works of De Morgan, Quetelet, Galton, Poincaré, Bernouilli and De Moivre.

Under the head of Belief and Evidence, there is no mention of Balfour's Defence of Philosophic Doubt or of Greenleaf's Treatise on the Law of Evidence.

John Grier Hibben.

PRINCETON UNIVERSITY. 